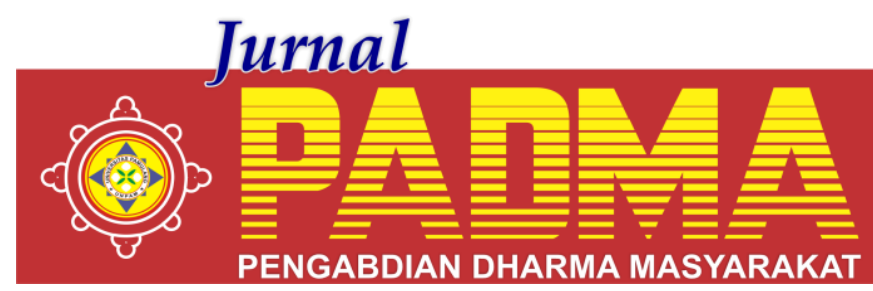

VOLUME 1, NOMOR 2, APRIL 2021

\title{
LITERASI PANCASILA DALAM SENI PERTUNJUKAN REAK DI KAMPUNG JATI, KELURAHAN PASIR BIRU, KECAMATAN CIBIRU
}

\author{
${ }^{1 *}$ Willfridus Demetrius Siga, ${ }^{2}$ Kristining Seva, ${ }^{3}$ Topik Mulyana, ${ }^{4}$ Tri Joko Her Riadi
}

Universitas Katolik Parahyangan, Bandung, Jawa Barat, Indonesia

*willy_d@unpar.ac.id

\begin{abstract}
Abstrak
Kebudayaan adalah salah satu komponen yang menunjukkan jati diri kita sebagai sebuah bangsa. Nilai kearifan lokal yang terkandung dalam seni budaya seyogyanya mampu mendorong semangat kecintaan pada kehidupan manusia dan bangsa. Kearifan lokal yang terkandung dalam seni dan budaya merupakan referensi yang bermanfaat, terutama dalam rangka edukasi generasi muda. Sementara di sisi lain, teknologi sebagai hasil kebudayaan yang bersifat fisik dianggap mereduksi nilai-nilai yang terkandung dalam adat istiadat, agama, dan kesenian. Faktor-faktor yang menjadi tantangan bagi budaya lokal adalah perubahan tata nilai-nilai budaya dalam masyarakat serta matinya bentuk-bentuk seni tradisi di Indonesia, khususnya Jawa Barat, yang disebabkan oleh ideologi digital dan acuhnya generasi muda akan pentingnya nilai seni dan budaya lokal. Maka, dipandang perlu menumbuhkan kesadaran bagi generasi muda untuk lebih memahami budaya yang dimilikinya melalui edukasi seni pertunjukkan reak. Merujuk pada fenomena-fenomena di atas, kegiatan pengabdian ini menggunakan pendekatan kualitatif yang dianalisis secara deskriptif. Pencarian atau pengumpulan data dilakukan melalui observasi, wawancara, dan studi pustaka guna mendalami seni Reak sebagai ritual, hiburan, dan memperkokoh integritas kebangsaan berdasarkan semangat Pancasila.
\end{abstract}

Kata Kunci : Nilai, Kebudayaan, Kearifan Lokal, Reak, Pancasila, Disrupsi

Culture is one component that shows our identity as a nation. The value of local wisdom contained in cultural arts should be able to encourage a spirit of love for human life and the nation. Local wisdom contained in art and culture is a useful reference, especially in the context of educating the younger generation. While on the other hand, technology as a physical cultural product is considered to reduce the values contained in customs, religion and art. Factors that challenge local culture are changes in cultural values in society and the death of traditional art forms in Indonesia, especially West Java, which is caused by digital ideology and the youth's indifference to the importance of local artistic and cultural values. Thus, it is deemed necessary to raise awareness for the younger generation to better understand their culture through education on reak performing arts. Referring to the above phenomena, this service activity uses a qualitative approach which is analyzed descriptively. Search or data collection is carried out through observation, interviews, and literature study in order to explore the art of Reak as a ritual, entertainment, and strengthen national integrity based on the spirit of Pancasila..

Keywords: Values, Culture, Local Wisdom, Reak, Pancasila, Disruption.

\section{PENDAHULUAN}

Generasi muda saat ini terkesan tercerabut dari akar seni dan dan budaya lokal. Persoalan ini menjadi semakin rumit, ketika migrasi budaya luar yang menawarkan nilai baru yang dibenturkan dengan kearifan lokal yang terkesan menggantikan nilai-nilai kearifan budaya lokal dengan nilai yang baru tanpa melewati tahap filterisasi secara kritis rasional.

Asumsi di atas diperkuat dengan pendapat Alvin Boskoff (1964) bahwa faktor-faktor yang menjadi tantangan bagi budaya lokal adalah perubahan tata nilai budaya dalam masyarakat, serta matinya bentuk-bentuk seni tradisi di beberapa wilayah Nusantara, yang disebabkan oleh ideologi digital. Unsur keterbukaan sebagai salah satu refleksi dari sifat Pancasila memungkinkan adanya interaksi budaya Nusantara dengan budaya luar.

Fenomena di atas menjadi alasan pemilihan pertunjukan seni Reak Tibelat, sebagai salah satu seni pertunjukan budaya 
Nusantara yang sarat dengan nilai-nilai luhur Pancasila. Ketekunan masyarakat sekitar untuk terus memelihara seni pertunjukan ini merupakan cerminan kuat nilai luhur Pancasila. Menurut pendapat Soetarjo Kartohadikoesoemo (1984), bahwa falsafah Pancasila perlu dipertahankan dan dikembangkan, karena perkembangan suatu bangsa akan sejahtera dan sempurna jika dilandaskan atas kultur budaya nasional, dan oleh karena kultur budaya barat yang dibawa oleh penjajah selama tiga setengah abad justru tidak memberi kepuasan batin, melainkan membawa umat manusia di dunia Barat kepada kerusakan dan keruntuhannya.

Literasi berpancasila melalui seni pertunjukan reak yang bertujuan: (1) Membantu mengangkat sisi rasionalitas kearifan lokal ke tatanan akademik, (2) Mengembangkan desa literasi Pancasila berdasarkan nilai-nilai kearifan lokal melalui seni pertunjukan, (3) Edukasi kesenian Reak kepada generasi muda, (4) Mendorong generasi muda untuk mengenal jati diri melalui kearifan lokal, (5) Memperkuat eksistensi seni pertunjukan Reak.

Seni Pertunjukan Reak TibelatSecara historis, eksistensi Reak dimulai sejak Abad ke-18 yang berasal dari wilayah Pantura, Indramayu, dan Cirebon. Reak mulai merambah ke Sumedang melalui para pedagang, kemudian masuk ke wilayah Cibiru pada tahun 1930 dan mulai berkembang di tahun 1964. Kata Reak berasal dari kata areakeakan yang artinya sukacita, sorak sorai (Rohidi, 2016). Oleh karena itu, tak heran jika saat itu Reak sering dipakai untuk hajat lembur atau sebagai ritual ketika masyarakat panen padi sebagai bentuk ungkapan syukur dan sukacita. Abah Enjum adalah ketua lingkungan seni Reak Tibelat, Kampung Jati, Kelurahan Pasir Biru, Kecamatan Cibiru. Beliau memiliki perhatian lebih terhadap seni Reak, yang di percaya merupakan tradisi peninggalan leluhur.

Meskipun zaman sudah berubah tetapi kesenian dan tradisi tetap ada, seperti pribahasa Sunda ngigeulan zaman sareng ngigelkeun zaman. Artinya mengikuti zaman tapi ketradisiannya masih tidak berubah. Ada lima (5) alat waditra dogdog masingmasing memiliki sebutan yang berbeda yakni tilingtit, tong, brung, bangplak, dan bedug. Jika kelima alat musik tersebut dimainkan, akan menghasilkan bunyi yang ditafsirkan menjadi kalimat gera indit tong embung, gera tumamprak lamun bedug enggeus datang. Artinya, sebagai manusia harus selalu ingat dari mana kita berasal.

Terdapat unsur warna pada topeng Berokan/Bangbarongan yaitu merah, putih, kuning dan hitam yang menggambarkan papat (empat) unsur, juga menggambarkan tata letak geografis seperti barat, timur, selatan, yang dalam tradisi masyarakat Jawa Barat disebut papat kalima pancer. Kalima adalah orang yang menggunakan Topeng Berokan/Bangbarongan, dan pancer yaitu kembali lagi pada yang Maha Kuasa, Sang pencipta alam semesta. Selain penjelasan di atas dari beberapa unsur juga terdapat saripati yaitu aci bumi, aci cai, aci angin, dan aci seneu, sebagai saripati daripada warna yang melekat pada topeng Berokan/Bangbarongan.

Pertunjukan berokan diawali dengan kidung dalam Bahasa ibu (Indramayu atau Cirebon), dilanjutkan dengan tarian Berokan yang lambat, perlahan-lahan untuk kemudian menjadi naik turun dan bergairah. Pertunjukan Berokan biasanya ditambahi juga dengan aksi menegangkan yaitu dengan menambahkan pecahan kaca (beling) dan kemudian penari topeng Berokan akan menari di atas pecahan kaca tersebut, tak hanya berhenti di situ, agar terlihat lebih menarik dan menegangkan penari akan lanjut menari di atas bara api. Berokan/Bangbarongan juga diiringi oleh serangkaian musik yang sederhana, terdiri dari: kendang, terebang, kecrek dan bende (gong kecil) yang dimainkan oleh enam orang. Musiknya memang terasa monoton, namun demikian dinamika kadangkala muncul dari kendang dan kecrek kemudian saling bersahutan dengan suara yang ditimbulkan dari topeng berokan yang berbunyi (plok-plak-plok). Karakter yang ada dalam topeng tersebut yaitu, merah sebagai tanda ia memiliki keberanian serta amarah yang cukup tinggi, mata dan kumis yang terdapat pada topeng tersebut semakin mejelaskan kemarahan atau amarah serta kumis sebagai ciri dari kesombongan, jika diartikan secara keseluruhan ialah topeng berokan dapat membuat siapapun yang memakainya bisa menjadi murka, marah, egois picik/licik dan ingin menang sendiri. 
Topeng yang dibuat tidak sembarang, melainkan harus melalui proses atau ritual tertentu kepada leluhur dengan cara mipit atau widi (ngarekes ritus dan ritual untuk mendapatkan hasil yang sempurna atau disebut nyurup yang artinya seimbang).

\section{METODE}

Menurut Jaeni (2012), seni pertunjukan diciptakan bukan tanpa kesengajaan, tetapi ia diciptakan berdasarkan nilai-nilai, pandangan dunia, serta kepercayaan seniman dan publik sebagai bagian dari suatu aktivitas sosiokultural masyarakat. Nilai-nilai seni dan kebudayaan masyarakat dalam seni pertunjukkan inilah yang kemudian akan diperdalam dan diangkat ke tataran literasi berpancasila sebagai karifan lokal secara khusus menyasar generasi muda yang dianggap mulai mengalami krisis pemaknaan nilai-nilai yang berbasis kebudayaan dan tradisi lokal. Pengabdian ini menggunakan pendekatan etnografi melalui in-depth interview, focul group discussion, dan pengamatan secara langsung di lapangan merupakan metodologi yang digunakan untuk menganalisis nilai-nilai Pancasila dalam seni pertunjukan Reak, peluangnya, dan relevansinya bagi generasi saat ini.

\section{HASIL DAN PEMBAHASAN}

Alur keseluruhan proses pagelaran seni pertunjukan ini digambarkan dalam bagan berikut ini yang diadaptasi dari Hermana (2014), dengan beberapa penambahan dari hasil wawancara dan observasi:

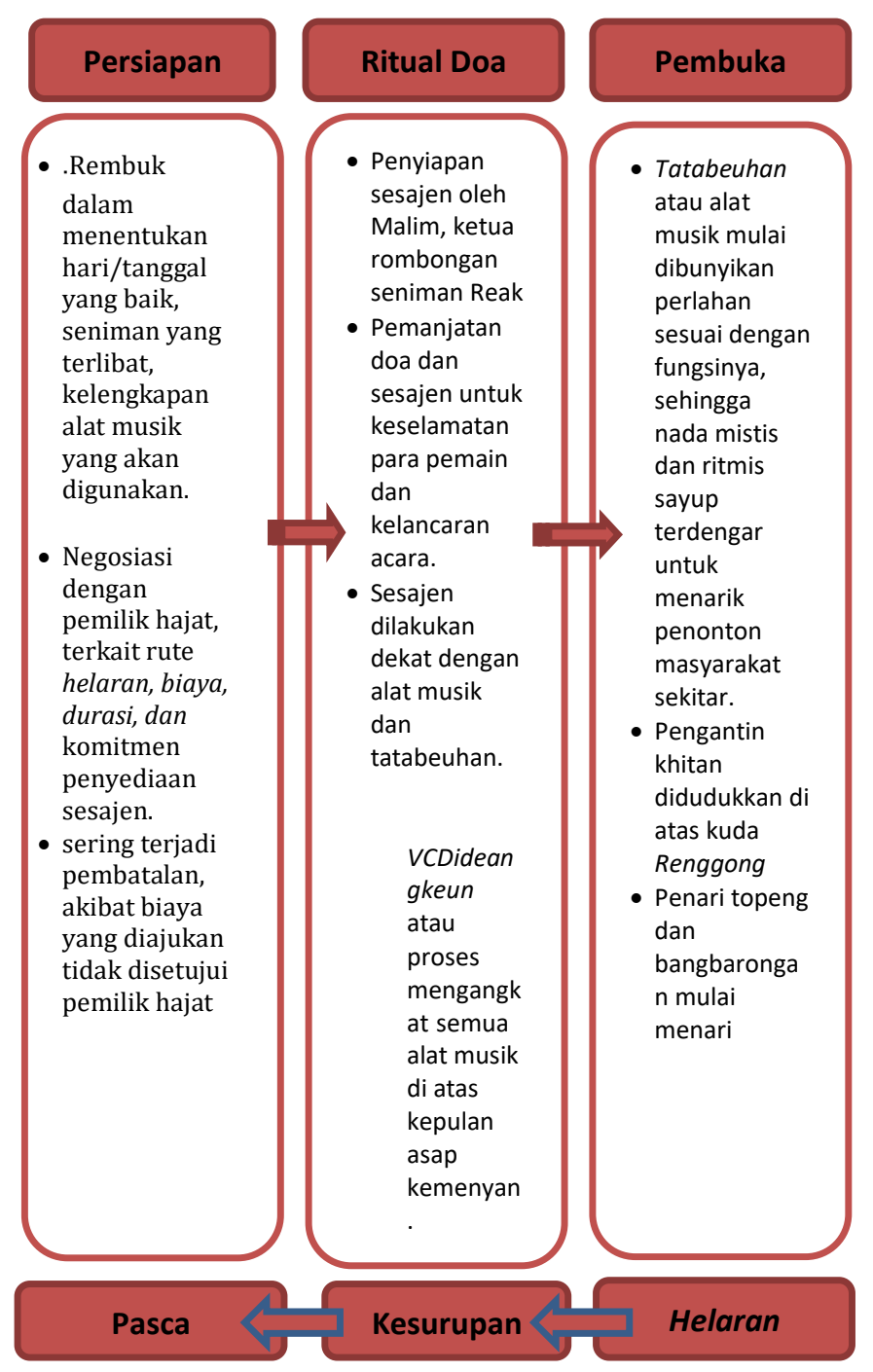

Gambar 1. Alur Proses Pagelaran Seni Pertunjukan 
Kesenian Reak ini merupakan ekspresi senimannya yang dibuktikan dengan beberapa gerakan alami/natural para penarinya dengan penghayatannya masingmasing (fungsi pribadi) yang pada puncaknya terjadi kerasukan.

\section{Nilai Pancasila dalam Seni Pertunjukan Reak}

\section{Dimensi Religiusitas}

Dimensi sila pertama ini erat kaitannya dengan nilai religius yang terkandung dalam seluruh proses pertunjukan Reak. Nilai religius yang bersumber pada keyakinan manusia terhadap kekuatan yang di atas, tercermin dalam beberapa hal, walaupun tidak sepenuhnya berkaitan dengan keagamaan.

Hal senada juga diungkapkan oleh Jocob Sumarjo (2006), bahwa, estetika dalam seni pertunjukan adalah estetika iman. Iman merupakan peningkatan religius dalam keagamaan yang berarti estetika iman merupakan wujud keindahan yang berdasarkan nilai religi.

\section{Dimensi Kemanusiaan}

Sarat dengan nilai humanism universal, sila kedua ini praktis hampir selalu tertuang dalam setiap tahapan pertunjukan seni Reak. Adanya kelompok masyarakat yang mendukung pun merupakan nilai sosial yang melandasi keberagaman profesi, agama, dan kepercayaan yang hidup berdampingan di kawasan Cibiru, untuk ikut ngariung dalam pagelaran tersebut. Dengan kata lain, nilai yang terkandung dalam pertunjukan ini juga sejalan dengan nilai sila kedua yang menjunjung hak dan martabat yang sama dan sejajar.

\section{Dimensi Persatuan}

Sila Persatuan Indonesia tercermin dalam fungsi estetika yang terletak pada perpaduan gerakan, tata rias, tata busana, harmonisasi dan iringan musik dalam seni pertunjukan Reak. Keindahankeindahan masing-masing seni yaitu, seni reog, seni angklung, seni kendang pencak, seni tari dan seni topeng, terangkum secara padu dan satu sekaligus harmonis dalam Reak. Kesesuaian gerak penari dan iringan musik tersebut menjadi keselarasan tersendiri yang dapat dinikmati oleh masyarakat. Inilah esensi bhineka tunggal ika yang bermakna walaupun berbeda namun tetap satu.

\section{Dimensi Demokrasi}

Sila keempat tergambar dari sikap keterbukaan dalam penyelenggaran pertunjukan. Ada musyawarah untuk menentukkan para pemain, termasuk juga honor yang diperoleh. Semua dilakukan secara terbuka. Abah Enjum selalu terbuka terhadap pertanyaan-pertanyaan sekaligus kekhawatiran masyarakat mengenai adanya unsur-unsur kemusyrikan dalam Seni Reak. Beliau selalu bersedia untuk berdiskusi dengan pihak mana pun.

\section{Dimensi Keadilan Sosial}

Dimensi keadilan sosial tecermin melalui rasa puas, rasa senang dari para pemain/seniman dan para penikmat seni termasuk para penonton selama dan selesai pertunjukan. Dalam hal pembagian honor, Abah Enjum membagi rata honor untuk para pemain, baik untuk penari maupun pemusik. Yang menarik, pemain kecrek mendapatkan honor yang sama besar dengan pemain terompet, kecapi, dogdog, dan gong, padahal tampak sepele. Meski demikian, bagi Abah Enjum, tanpa kehadiran pemain kecrek, musik reak jadi kurang greget, kurang sempurna. Maka, pemain kecrek pun sama pentingnya dengan pemain lain.

\section{PENUTUP}

Kesimpulan dan Peluang Budaya Lokal di Era Disrupsi.

Literasi Pancasila dalam seni pertunjukan Reak tidak terlepas dari paradigma teknologi yang mengubah pola pikir dan cara bertahan hidup. Kita juga tidak dapat mengelak bahwa nilai-nilai tradisi lokal dituntut untuk bertransformasi jika tidak ingin tergerus oleh dinamika digitalisasi. Informasi, pengetahuan dan pelibatan (engagement) menjadi syarat mutlak. Pergeseran fungsi dari kertas (cetak) ke daring (online) begitu pula dari dunia 
pertunjukkan lakon panggung ke pertunjukkan secara daring (online) harus disikapi sebagai peluang baru bagi internalisasi nilai-nilai tradisi lokal.

$$
\text { Maka yang dibutuhkan adalah }
$$
keterbukaan dan kolaborasi yang mutual. Dengan cara ini, Seni tradisi bukan hanya menjadi tontonan semata, nilai-nilai kearifan lokal disebarluaskan, eksistensi komunitas lokal diangkat ke tataran global, dan menyumbang informasi terpercaya bagi pembangunan karakter generasi bangsa yang berkepribadian, kreatif, inovatif, kritis, dan komunikatif.

\section{DAFTAR PUSTAKA}

Agustina, Sintia Dewi (2020). Studi kasus pada Perubahan Bentuk Visual Topeng Berokan Sanggar Tibelat Cibiru.Bandung:ISBI (Dokumentasi Sanggar Reak Tibelat Cibiru

Boskoff, Alvin (1964). Recent Theories of Social Change dalam Weaner J. Cahnman \& Alvin Boskoff (ed.), Sociologi and History: Theory and Research, London: The Free Press of Glencoe.

Dabandjaja, James (2007). Folklor Indonesia. Jakarta: Grafiti. Hoed, Benny (2014). Semiotika dan Dinamika Sosial Budaya. Depok: Komunitas Bambu.

Dewanti, R. N., et al. (2021). Penyuluhan Dan Pelatihan Keterampilan Sablon Pigment Pasta Manual Di Karang Taruna 03 Desa Cisauk. Jurnal PADMA: Pengabdian Dharma Masyarakat, 1(1).

Hermana, Saftadi (2014). Pertunjukan Seni Reak Dogdog Grup Walet di Desa Ciburu Wetan, Kecamatan Cileunyi Kabupaten Bandung. www. perpustakaan.isbi.ac.id (diakses tanggal 10 September 2020).

Jaeni (2012). Kajian Seni Pertunjukan dalam Perspektif Komunikasi Seni. Bogor: IPB Press

(2015). Metode Penelitian Seni: Subjektif Interpretif Pengkajian dan Kekaryaan Seni. Bandung: Sunan Ambu STSI Press

(2017). Nilai-Nilai Pengetahuan Lokal Pembentuk Karakter Bangsa Dalam
Sandiwara Cirebon, Jawa Barat. Jurnal seni Budaya MUDRA. LP2M ISI Denpasar Bali. Volume. 32, No. 1 hal. 332.

Kartohadikoesoemo, Soetarjo (1984). Desa. Jakarta: Balai Pustaka.

Latif, Yudi (2014). Mata Air Keteladanan: Pancasila dalam Perbuatan. Jakarta: Mizan, 2014.

Rohidi, Tjetjep Rohendi (2016). Pendidikan Seni: Isu dan Paradigma. Semarang: Cipta Prima Nusantara.

Rosidi, Ajip (2004). Masa Depan Budaya Daerah. Bandung: Pustaka Jaya.

Ritzer, George (2004). The Globalization of Nothing. USA: Pine Forge Press.

Schirato, Tony dan Jen Webb (2003). Understanding Globalization. London: Sage Publication. (2002). Seni Pertunjukan Indoensia di Era Globalisasi, Yogyakarta: Gadjah Mada University Press.

Sugiarto, Eko, 2019. Kreativitas, Seni, dan Pembelajarannya. Yogyakarta: LKIS.

Sumardjo, Jakob. Filsafat seni. Bandung: Penerbit ITB, 1999.

(2001). Seni Pertunjukan Indonesia. Bandung: STSI Press (2014). Estetika Paradoks. Bandung: Kelir.

https://docplayer.info/53068599-

Fungsi-pertunjukan-seni-reak-di-desacinunuk-kecamatacileunyi.html

(diakses tanggal 15 September 2020). Reak, 2011 dalam http://www.disparbud.jabarprov.go.id /wisata/destdet.php?id=334\&lang=id) (diakses tanggal 15 September 2020). 